Article

\title{
Facebook's Emotional Contagion Experiment as a Challenge to Research Ethics
}

\author{
Jukka Jouhki ${ }^{1, *}$, Epp Lauk ${ }^{2}$, Maija Penttinen ${ }^{1}$, Niina Sormanen ${ }^{2}$ and Turo Uskali ${ }^{2}$ \\ ${ }^{1}$ Department of History and Ethnology, University of Jyväskylä, 40014 Jyväskylä, Finland; E-Mails: jukka.jouhki@jyu.fi \\ (J.J.), maija.s.penttinen@student.jyu.fi (M.P.) \\ ${ }^{2}$ Department of Communication, University of Jyväskylä, 40014 Jyväskylä, Finland; E-Mails: epp.lauk@jyu.fi (E.L.), \\ niina.sormanen@jyu.fi (N.S.), turo.uskali@jyu.fi (T.U.) \\ * Corresponding author
}

Submitted: 31 January 2016 | Accepted: 12 April 2016 | Published: 10 October 2016

\begin{abstract}
This article analyzes the ethical discussion focusing on the Facebook emotional contagion experiment published by the Proceedings of the National Academy of Sciences in 2014. The massive-scale experiment manipulated the News Feeds of a large amount of Facebook users and was successful in proving that emotional contagion happens also in online environments. However, the experiment caused ethical concerns within and outside academia mainly for two intertwined reasons, the first revolving around the idea of research as manipulation, and the second focusing on the problematic definition of informed consent. The article concurs with recent research that the era of social media and big data research are posing a significant challenge to research ethics, the practice and views of which are grounded in the pre social media era, and reflect the classical ethical stances of utilitarianism and deontology.
\end{abstract}

\section{Keywords}

Big data; emotional contagion; Facebook; informed consent; manipulation; methodology; privacy; research ethics; social media; user data

\section{Issue}

This article is part of the issue "Successes and Failures in Studying Social Media: Issues of Methods and Ethics", edited by Epp Lauk and Niina Sormanen (University of Jyväskylä, Finland).

(C) 2016 by the authors; licensee Cogitatio (Lisbon, Portugal). This article is licensed under a Creative Commons Attribution 4.0 International License (CC BY).

\section{Introduction}

In June 2014 the Proceedings of the National Academy of Sciences (PNAS) published an article entitled "Experimental Evidence of Massive-Scale Emotional Contagion Through Social Networks". It was about an experiment ${ }^{1}$ conducted by Adam D. I. Kramer from Facebook's Core Data Science Team together with Jamie E. Guillory and Jeffrey T. Hancock from Cornell University. The article provided experimental evidence about emotional contagion, a phenomenon that has been widely studied before but mostly in offline environments. In January 2012, the research team manipulat-

\footnotetext{
1 Henceforth, "the Facebook experiment" or "the experiment".
}

ed the News Feeds of a massive number $(N=689,003)$ of Facebook users for a week, reducing the amount of emotional content in their feeds. After analyzing over three million posts and over 122 million words, the results showed that when the amount of positive status updates published in their News Feed was reduced, users published more negative status updates and fewer positive updates. Conversely, when the amount of negative status updates was reduced, users published more positive status updates and fewer negative updates. Moreover, the less emotional content the users were exposed to, the fewer words they used in their status updates. (Kramer, Guillory, \& Hanckock, 2014).

The research suggested that emotional states "can be transferred to others via emotional contagion, lead- 
ing people to experience the same emotions without their awareness" (Kramer et al., 2014, p. 8788). Emotional contagion had been proved earlier (e.g. Barsade, 2002; Huntsinger, Lun, Sinclair, \& Clore, 2009; Kramer et al., 2014, p. 8788 also refer to several other studies), but proving that it happens "outside of in-person interaction" and particularly in the increasingly popular social media was new (see e.g. Ferrara \& Yang, 2015 for a similar but more recent study). Moreover, as there are common conceptions about positive social media postings making people sad or envious (e.g. Copeland, 2011), the experiment produced valuable information to the contrary. The experiment suggested that people's "hearts and minds", as Schroeder (2014, p. 3) puts it, can be manipulated online, for good or ill. (See also Shah, Capella, \& Neuman, 2015; Summers-Effler, Van Ness, \& Hausmann, 2015, p. 472; cf. Parkinson \& Manstead 2015, p. 377.)

Academic and non-academic reactions to the study-defined as ethically controversial (Ananny, 2015, p. 101; Harriman \& Patel, 2014; Pejovic \& Musolesi, 2015, p. 18; Simon, 2014; Thorson \& Wells, 2015, p. 10) - were mixed. On a broader view, the heterogeneity of the views on the ethics of the experiment is a sign of how contested and fluid the concept of privacy is (e.g. Ess, 2013, p. 260). Moreover, as Facebook cooperates with several universities such as Cornell, Stanford and Harvard (see e.g. Cheng, Adamic, Dow, Kleinberg, \& Leskovec, 2014; Friggeri, Adamic, Eckles, \& Cheng, 2014; Sun, Rosenn, Marlow, \& Lento, 2009) ${ }^{2}$ the experiment has raised debate about whose research ethics prevail in such joint ventures-those of a private company or those of an academic research institution. In this article, we focus on the academic but also look to some extent at the non-academic ethical commentary on the Facebook experiment, and ask what it tells us about ethical research issues in the current era of social media research.

The ethical discussion presented in this article is founded on an integrative literature review (see e.g. Card, 2010; Torraco, 2005) that we conducted by searching major journal databases such as Science Direct, Google Scholar, Sage Journals, and Ebsco Academic Search Elite for articles covering the experiment. As a result we obtained articles from journals such as $R e$ search Ethics; Big Data \& Society; Media, Culture \& Society; Nature; and Information, Communication \& Society. In addition to journal articles, we searched for conference proceedings on the experiment as well as scholarly analyses of the issue published in blogs and

2 For Stanford's recent collaboration with Facebook, see www.sserg.org/new-collaboration-with-stanford-universityand-facebook. More about Facebook's partnerships at https:// research.facebook.com. On Facebook's exclusive cooperation with a few universities that have been granted access to Facebook's data, see e.g. Paolillo, 2005, p. 50. other internet sites. Some news and magazine articles as well as blog posts were also included in order to offer some non-academic views on the issue.

Overall, our approach to the ethical discussion revolving around the Facebook experiment is essayistic in nature (see e.g. Ceserani, 2010; Cornelissen, Gajewskade, Piekkari, \& Welch, 2012, pp. 198-199), which means that we prefer exploring and discussing the topic in a heuristic manner: we tend to concentrate on raising questions rather than put forward any definite results based on empirical research. However, we do argue that there are two crucial themes of debate which sum up the ethical discussion revolving around the experiment: research as manipulation (discussed in Section 3) and the related informed consent (discussed in Section 4). Moreover, we suggest that the debates about the ethics of human-subject big data research, while demanding a rethink of research ethics, still reflect the classical divide between the utilitarian and the deontological points of view. In the next section we will introduce some key questions of research ethics in the era of social media. Then we move on to present the Facebook experiment and the ensuing ethical discussion. ${ }^{3}$

\section{Research Ethics and the Human Subject}

The views on research ethics generally put into practice in any academic research can be seen as balancing between two classic moral philosophical stances. Utilitarianism attempts to calculate the morality of an act by estimating the total amount of happiness or suffering produced by the act, while deontology views certain actions as immoral or moral per se, regardless of their consequences. Both these stances are applied, for example, in social media research when scholars contemplate the effect of their study on the subjects' privacy: the utilitarian view of privacy might allow certain incursions into privacy if the result is the greater good, whereas from the deontological point of view, a certain level of privacy is a right that should not be violated, for example, by conducting a study without receiving the informed consent of the subjects of the study (Ess, 2013, pp. 256-262; Shrader-Frechette, 2000). Both stances are problematic, and neither of them is applied in research without any consideration of the other-or in moral decision-making outside of academia, for that matter. At any rate, the utilitarian emphasis on avoidance of harm and the more deontological value of receiving informed consent from research subjects are considered the two most significant imperatives of research ethics in studies with human participants (e.g. the British Psychological Society, 2010). Actual policies as to how exactly the imperatives are defined and in what situations they apply (e.g. in big data research) vary significantly.

${ }^{3}$ This article is based on an unpublished conference paper by Jouhki et al. (2015). 
One of the key ethical principles of the Association of Internet Researchers (AolR)-that the greater the vulnerability of the subject of study, the greater the obligation of the researcher to protect the subject-is a good example of how challenging it is to formulate specific rules of ethical research (Markham \& Buchanan, 2012, pp. 4-5). Obviously, protecting the research subject depends on how one defines both the harm that might be inflicted on the unprotected person and also a research subject. The context of any research setting means that ethical codes are not so much strict rules as incentives to individual researchers to reflect on the moral ground of their research and make ethical decisions using their own judgment of what is in fact practicable in the circumstances. Especially when informed consent cannot be obtained in human-subject research, the benefits of the study should outweigh the harm of any invasion of privacy.

Often anonymity is seen as enough to ensure the no-harm rule in cases of non-experimental (e.g. purely observational) research. In experiments that affect the participants' behavior, the rules are stricter (See e.g. Vainio, 2012; Vanderpool, 1996.). The level of sensitivity required for the decision-making to be ethically sufficient is a constant topic of debate. For example, a research institution or a commercial company engaging in research might hold the view that obeying the law is enough to make the research ethical (Hudson \& Bruckman, 2004, pp. 132-133). If the participants are not harmed in any way during the data gathering, an ethically sensitive researcher-whether working in a private company or a university-might still take into account the hypothetical situation that a research participant at some point learns about his or her role in the research and is offended (i.e. harmed) by having been a participant without having given consent (e.g. Hudson \& Bruckman, 2004, pp. 136-138). Moreover, an ethically sensitive researcher might treat public content on the internet (e.g. tweets, blog posts) as intimate parts of their creator's personhood. Most researchers, however, use this content without securing informed consent (Hesse, Moser, \& Riley, 2015, p. 27).

The fact that data are accessible and public does not necessarily mean that using them is not jeopardizing privacy and is thus ethically justified (see e.g. boyd, 2010; ${ }^{4}$ Marx, 2013; Tinati, Halford, Carr, \& Pope, 2014, p. 673; Zimmer, 2010). The boundaries between private and public information-especially on the internet-are frustratingly ambiguous, contested and changing (Markham \& Buchanan, 2012, p. 6; Ess, 2007, p. 499; see also Rooke, 2013; Rosenberg 2010; Weeden, 2012, pp. 4243). Even when a researcher wants to have participants' informed consent to take part in a study, it might be impossible for him or her to obtain it if the research in

${ }^{4}$ The author danah boyd wants her name to be written in lower case. question concerns, for example, massive data mining processes and projects. Moreover, big data researchers often ignore the whole question of informed consent because they define their data as either public or proprietary (Paolillo, 2015, p. 49). Also, when there is no direct contact between the researchers and their human subjects it is questionable whether the subjects should even be called participants. Besides, when experiments are made on them, it is unclear whether they are to be subject to the same ethical research scrutiny as human-subject study participants normally are (Hutton \& Henderson, 2015, p. 178; Kahn, Vayena, \& Mastroianni, 2014, p. 13677.). Even if a researcher did in such cases manage to obtain the participants' consent, there would be no real guarantee that it was indeed informed (Flick, 2016, p. 15-17).

To problematize the issue further, even if informed consent was verified and the researcher was allowed to use the participants' personal data, the data might also include information about people (e.g. contacts of the users) who had not given their informed consent (Phillips, 2011, p. 32). Thus it is no surprise that a large number of extensive data mining projects are carried out without informing the groups or individuals targeted by the researchers; the only measure taken to promote the ethicality of the research is making sure that the participants are anonymous, thus ensuring confidentiality (Lindsay \& Goldring, 2010; Zwitter, 2014, p. 5; see also Sormanen et al., 2016).

In contrast, when conducting qualitative research like virtual ethnography or, more specifically, participant observation, in smaller internet forums, obtaining the consent of participants is technically relatively easy. However, it is rarely done because of the possibility that knowing that they are being observed might cause participants to act differently from usual, which would skew the data. Then again, in practice, many scholars do not seek informed consent because they are afraid it would be denied (e.g. Hine, 2000, pp. 2324.). Sometimes participant observation even without consent is impossible (e.g. in the case of private discussion groups), so the researcher might engage in deception (e.g. an invented alias) in order to gain access to the group of participants. As Brotsky and Giles (2007, pp. 95-96) put what is indeed rather obvious, covert participant observation is "highly controversial from an ethical position", but as in most completed research projects with ethical research challenges, it is ultimately justified by reference to the benefits brought by the results. Sometimes even informed consent does not create an authentic consensual atmosphere, for example if the subjects of the research do not feel they have been treated fairly or if the purpose of the research is not felt to be morally valuable enough (Kennedy, Elgesem, \& Miguel, 2015). Lastly, even if informed consent is received, there is the problem of the level of informedness. How can a researcher be sure that the 
research subject has sufficiently understood the purpose and the consequences of the research? (E.g. Escobedo, Guerrero, Lujan, Ramirez, \& Serrano, 2007; Svanteson, 2007, p. 72.)

\section{The Facebook Experiment as Manipulation}

On Facebook, the News Feed is practically a list of status updates of the contacts in a user's network. The updates shown in or omitted from the News Feed depend on "a ranking algorithm that Facebook continually develops and tests in the interest of showing viewers the content they will find most relevant and engaging". Facebook is thus like any traditional media as it provides content to its users selectively, but where it differs from the old media is that the content is modified individually according to what the medium evaluates to be the optimally engaging experience. (Kramer et al., 2014, p. 8788.) Users accept this practice when signing up for Facebook.

In their massive-scale experiment, Kramer et al. (2014) tested the emotional engagement of Facebook users by modifying their News Feed. The "experiment on the manipulative power of Facebook feeds", as Peacock (2014, p. 8) described it, was criticized almost immediately upon publication of the article. Bloggers claimed Facebook made users "sad for a psych experiment" (Grimmelmann, 2014) or the company was using people as "lab rats" (a blogger quoted by Rushe, 2014). According to The Guardian's poll (Fishwick, 2014), most people who read about the experiment were not surprised that Facebook would experiment on user data the way it did but, at the same time, they declared they had now "lost trust" in Facebook and were considering closing their account. The "secret" experiment, as The Guardian called it, "sparked outrage from people who felt manipulated by the company". It can be speculated that had Facebook known what the public reaction to their experiment was going to be, they would not have published it. danah boyd (2014; see also Paolillo, 2015, p. 49) suggests that the intended PR outcome of the experiment from Facebook's point of view was to show that Facebook can downplay negative content in their service and thus make customers happier. Presumably this was seen as better for users and better for Facebook, as experimentation is how websites make their services better (Halavais, 2015, pp. 689-690; Kahn et al., 2014, p. 13677).

It is possible that many people missed the benevolent intention of the research team and concentrated on the contestable ethics of their method. The criticism about the experiment reached such levels that Facebook's researcher and the first author of the article, Adam Kramer, defended the experiment in his own Facebook page, pointing to the minimal "actual impact on people". During the week of the experiment, he explained, the users who were affected "produced an av- erage of one fewer emotional word, per thousand words". (Kramer, 2014.) The magnitude of the impact was perhaps unknown to many critics of the experiment, as many objected to it on the grounds that Facebook was "controlling the emotions" of its users. Moreover, regardless of the magnitude of the impact of the experiment, the user agreement of Facebook can be interpreted to mean that users of Facebook allow researchers to experiment on them.

Thus, many ethicists would agree with Meyer (2014), who published a statement with five co-authors and on behalf of 27 other ethicists "to disagree with these sweeping condemnations" of Facebook's ethics in the experiment. She wrote that "the experiment was controversial, but it was not an egregious breach of either ethics or law." If Facebook is permitted to mine user data and study users for personal profit but academics are not permitted to use that information and learn from it, it "makes no one better off" (Meyer, 2014). However, for many critics it was more a matter of ethical principle than actual impact. For example, Kleinsman and Buckley (2015, p. 180) rejected Meyer's statement and claimed that "[i]f an experiment is in 'breach of either ethics or law,' then whether it is an 'egregious' breach or not is irrelevant." In this view, there is no grey area in research ethics, and consequently, a person as a subject of research is -in a binary way-either harmed or not harmed.

Many scholars were even more critical than Kleinsman and Buckley (2015). Recuber (2016), for example, noted how quick scholars were to draw analogies between the Facebook experiment and the infamous Milgram's (1963) experiment analyzing obedience to authority, as well as to the Stanford Prison experiment, also known as the Zimbardo experiment (Haney, Banks, \& Zimbardo, 1973; Zimbardo, 1973), that studied the psychological effects of becoming a prisoner or a guard. According to Recuber, there were indeed some similarities between the Facebook experiment and the two notorious experiments from the 1960s, one being the fact that all three studied the researchers' ability to manipulate change in the participants' behavior. However, the Facebook experiment was different in its failure to reflect on this aspect (Recuber, 2016, pp. 46-47). The user reactions studied in the Facebook experiment were caused by the observers but the power relations between the experimenters and the experimentees were downplayed or normalized, and not at all problematized. This, at least to Recuber, is a typical and insidious element of contemporary big data research. (Recuber, 2016.) When the number of research subjects is so high, individually they tend to vanish in the haze of the overarching term "big data". However, the "power" exerted per capita over the participants in the Facebook experiment can be viewed as rather minimal (albeit massive in scale). The experiments carried out by Milgram and Zimbardo, on the other hand, caused 
their participants to suffer severe physical and psychological stress.

The ethics of human-subject research is mainly about protecting the subject. In this sense, the Facebook experiment was found ethically questionable. Strict assessments of the experiment conclude that the study indeed "harmed" its participants (albeit almost unnoticeably), because it changed the participants' mood (e.g. Bryman \& Bell, 2015, p. 141; Grimmelmann, 2014; Kleisman \& Buckley, 2015, p. 181). However, if harming is defined as changing a participant's mood, then a vast quantity of empirical research on humans is harmful, especially research that requires face-to-face interaction. In general, big data studies or techniques to test or predict personality or actions might not be legally problematic but they do undermine a "sense of individuality on a personal level", claims Schroeder (2014, p. 7).

Facebook has experimented on its users before, and has published research about it (see e.g. Bond et al., 2012; Chan, 2015, p. 1081; Simonite, 2012). However, these experiments were explicit in their intention to influence users. For example, in 2010 on the day of the US congressional elections, Facebook encouraged randomly assigned users to vote, managed to increase voting activity, and afterwards published an article about it in Nature (Bond et al., 2012). Moreover, in 2012 Mark Zuckerberg, the CEO of Facebook, used Facebook to encourage people to register as organ donors, after which organ donor enrollment increased significantly in the US (Simonite, 2012). These forms of "manipulation" did not raise as much ethical debate as the experiment we discuss here did. The reason for this might be that people see explicit forms of intended manipulation as more acceptable than covert forms, even if the explicit manipulation attempts to elicit significantly greater change in the subject than the covert form.

Research ethics are often implemented more strictly in the academic world than in the corporate research environment. Then again, the ethical views of social media users might be quite flexible, and a lot of how users relate to being studied and experimented on by researchers depends on the application of the results (Kennedy et al. 2015, pp. 8-10). It seems like people do not want to be experimented on for the sake of an experiment but they are more likely to accept it if the experiment might result in some kind of benefit for themselves or others. Many people also do not mind commercials or other manipulations-even outright propaganda-as they are often part of the deal between users and service providers (cf. Searls 2015 on ad blockers). In the case of the Facebook experiment, even though scholars did not read any status updates, some people still felt that their privacy was violated. The problem in these kinds of cases is often the fact that one has a feeling of being private while actually being public (Kennedy et al., 2015, p. 13). According to Chan $(2015$, p. 1080), the fact that neither Facebook nor Cornell University-the two parties involved in conducting the study-apparently anticipated the public backlash they would face for the data manipulation shows "the vast disconnect between the research culture of big data (whether based in corporate or academic institutions) and the general public's cultural expectations."

\section{The Problem of Informed Consent}

It is the "informed" in informed consent that is the other major ethical research issue in the experiment that worried both the general public and academia (see e.g. Kahn et al., 2014, p. 13677). Cornell University researchers (Guillory and Hancock) analyzed the data after Facebook (Kramer) had collected them. The study therefore did not go through an ethical review at Cornell University, which might have been critical of how the informed consent of the participants was going to be secured (Paolillo, 2015, p. 50). In the article, research ethics is discussed in two sentences (Kramer et al., 2014, p. 8789). The first sentence states that the researchers themselves did not read any of the texts analyzed for the experiment as a linguistic software program was used to analyze the data. The other sentence declares that the data collection "was consistent with Facebook's Data Use Policy, to which all users agree prior to creating an account on Facebook, constituting informed consent for this research." In other words, the authors interpreted Facebook's user agreement to mean informed consent.

In that case, the level of informedness is highly debatable, as most users of Facebook do not read or completely understand the data use policy (Flick, 2016, p. 17; see also Kennedy et al., 2015, pp. 10-15). When a user accepts the terms and signs up for Facebook, he or she is informed that the service provider will use the personal data for all sorts of things (Facebook, 2015a). The user might give their consent but is most likely not well informed, since the description of the data use policy is not very precise (see e.g. Grady, 2015, p. 885; Sloan, Morgan, Burnap, \& Williams, 2014, p. 16.). For example, at the time of the experiment, the research use of personal data was not mentioned although, following the wide publicity the experiment received, it has subsequently been added to the policy.

Kleisman and Buckley (2015; see also Bail, 2015, p. 23) hold the view that because the authors of the Facebook experiment could have asked for proper informed consent from the users, they should have done so. It does not matter whether the research is unlikely to cause harm or if it is beneficial or otherwise important: consent is always essential if it can be obtained. The scholars should at least have informed those users who were affected afterwards (Recuber, 2016, p. 54; see also McKelvey, Tiessen, \& Simcoe, 2015, pp. 580-581). A month after the publication of 
the experiment, PNAS's Editor-in-Chief, Inder M. Verma (2014), added a foreword to the contested article. It was entitled "Editorial Expression of Concern and Correction" and it defended the authors' ethical choices by separating Facebook's data collection process from the actions of Cornell University. Readers were reminded that it was a non-academic private company (= Facebook's Kramer) that gathered the data, and the academics (= Cornell's Guillory and Hancock) only analyzed them. However, as the responsibility fell partly on the journal (see e.g. Kahn et al., 2014, p. 13679), Verma (2014, p. 10779; see also Schroeder, 2014, pp. 2-3) did concede that perhaps everything was "not fully consistent with the principles of obtaining informed consent and allowing people to opt out."

Many human-subject big data scientists know that a strict interpretation of the opting-out option makes their research extremely difficult. The problem is further complicated by the fact that in many cases the data are not collected by academics but by third parties such as Facebook. Should the data collectors abide by the ethical research norms of academia? If they did, there would be a lot of ethical problems, particularly with data produced by third parties, such as filmed footage, photographs, Google Street View data, televised rock concert recordings, and so on. Even if participant anonymity was secured, the human subjects in these cases could not opt out. If scholars did not have to worry about opting out as an ethical norm, they could team up with someone outside of academia to do their "dirty work" (see e.g. Kahn et al., 2014, p. 13677; Wrzus \& Mehl, 2015, p. 264; cf. boyd, 2014.). On the other hand, one could say that a person can opt out of any Facebook experiment by not signing up for Facebook in the first place-just like a potential participant in a psychology experiment can decide not to attend the experiment if he or she does not want to be manipulated.

In general, an ethically pragmatic social media user's informed consent is more like meta-informedness, or "implicit informed consent" (Bryman \& Bell, 2015, p. 139), where the user knows that for example Facebook will do various known and unknown things with its user data but is unlikely to do anything that is morally too dubious-although it has been observed that users tend to underestimate the level of their privacy when they are excited about a social media application (Kehr, Kowatsch, Wentzel, \& Fleisch, 2015). For most users, Facebook's data policy is thus a reasonably informed and fair trade-off between the user who gets to use the service without a fee, and the service provider who gets to sell the data to third parties such as advertisers (Kennedy et al., 2015, p. 12; see also Hutton \& Henderson, 2015, p. 178). This is actually the common logic of commercial media, and the "ethical fig leaf" (O'Hara, Nguyen, \& Haynes, 2014, p. 4) of a social media researcher.

As Chan (2015, p. 1080; see also Aiken \& Mahon, 2014 , p. 4) notes, Facebook's data use policy "enables any user to potentially become an experiment subject without need for prior consent". In the end, a scholar interested in research ethics might ask if there is anything ethically new in the Facebook experiment. People were studied without their knowing about it but they had allowed it by signing up for Facebook. (Schroeder, 2014, p. 3; see also Zwitter, 2014, p. 1.) Certainly companies have been doing experiments with only vaguely informed consent before, as have psychologists, so many people think the Facebook experiment is merely a recent example of an old ethical research issue (Schroeder, 2014, pp. 1-2; cf. Selinger \& Hartzhog, 2016).

In a way, the Facebook user agreement is similar to the informed consent form the participants in most psychological experiments have to fill out. Participants are informed that they (and the data they will produce) will be used for scientific purposes but the participant might not know exactly what those purposes are. He or she might even be deceived about the real purpose of the study to which they have consented. The message of informed consent is, "I trust you. Do what is needed." Perhaps the only new aspect in this case is that there are over a billion people on Facebook every day. It is an essential networking tool for a large amount of people, many of whom are dependent (to a greater or lesser extent) on the service. This means that its user agreement is not necessarily an ethical act between two equal parties: opting out of an experiment becomes equal to opting out of a significant part of one's social life (see e.g. Gertz, 2016). One might therefore suggest that a participant might be sufficiently informed but the question of consent is more controversial.

After multiple critical reviews of the experiment, Mike Schroepfer, the Chief Technology Officer for Facebook, wrote an apologetic post for Facebook's Newsroom. According to him, they should have "considered non-experimental ways" to do the research. Also, the research would have "benefited from more extensive review by a wider and more senior group of people". Schroepher also notes that they did not inform the public about the experiment well enough (Schroepfer, 2014). Schroepher also introduced a new framework of research that Facebook is going to implement. It included clearer guidelines for researchers, a more extensive review stage, and training (including on privacy and security matters), as well as the establishment of a special research website (Facebook, 2015b).

Describing the new guidelines section, Schroepher announced that a more enhanced review process would be conducted prior to research if the intended research focused on "studying particular groups or populations (such as people of a certain age) or if it related to content that may be considered deeply personal (such as emotions)." Also, a further review would be conducted if there was any collaboration with the academic community. The statement ends with trying to convince the reader-supposedly a daily Facebook 
user-that Facebook wants to do research "in a way that honors the trust you put in us by using Facebook every day." (Schroepher, 2014.) This seems to be Facebook's way of admitting that the experiment lacked informed consent. Perhaps for PR reasons as well as due to potential legal issues, Schroepher could not say outright that the experiment failed to obtain informed consent (cf. Verma, 2014).

\section{Discussion}

In this article we have shown how the debate around the Facebook experiment brings up two crucial and interrelated themes of research ethics: research as manipulation, and the problem of informed consent. The debate around the experiment shows that the era of big data research demands some rethinking of research ethics. Although the two key issues presented here are not unique to contemporary research but had been debated for decades before big data research came in (see e.g. Faden \& Beauchamp, 1986; Roelcke, 2004), the unprecedentedly large amount of human subjects that are called for in such research has led to a need for special scrutiny. At the same time, it seems that the ethical evaluation of such experiments is based on the classical ethical stances of utilitarianism or deontology. The proponent of the former sees little or no harm done in such an experiment and no loss of happiness caused by it, while the proponent of the latter considers that, regardless of the degree of actual harm, human integrity has been violated (see e.g. Ess, 2013, pp. 256-262; Harman \& Cornelius, 2015, p. 58; ShraderFrechette, 2000).

Reaching any ethical consensus about the Facebook experiment is further impeded by disagreements over the definition of key concepts such as the "harm" done to human subjects, and their "informed consent". When academic research ethics is so vague, it might seem simpler for scholars to leave it to the law and user agreements to define the ethics of the research. However, according to Chan (2015, p. 1082; see also Paolillo, 2015, p. 50; Burgess \& Bruns, 2015, p. 99), commercial companies' ethical research standards should not be allowed to spread to the academic world. Flick (2016; see also Halavais, 2015, p. 592) agrees and thinks that the commercial and academic sectors should negotiate and agree on standards, but without making any concessions in the commercial companies' favor. However, as universities' opportunities to cooperate with private companies working with big data increase, the opportunities to leave the problematic ethics of data collection to companies increase likewise.

Mike Schroepher, the Chief Technology Officer of Facebook, stated that Facebook should have communicated "clearly why and how" they did the experiment (Schroepfer, 2014). The statement implies that a person is deprived of optimal well-being if the reasons and methods of any actions carried out on him or her are not properly communicated. On the other hand, one could easily claim the opposite: a person suffers less when he or she does not know or notice anything about such actions. As Stilgoe (2015, pp. 46-47) observes, the Facebook experiment was rare in being openly published and publicly scrutinized, since most such experiments are conducted in secret. We can wonder if people were outraged about the experiment because Facebook altered its users' states of mind or because it reminded them that their states of mind are being altered all the time by all kinds of things, people and organizations (see e.g. boyd, 2016; see also Kehr et al., 2015).

At the same time, Kennedy et al. $(2015$, p. 2) observe that there has been little research about what social media users themselves actually think about being observed, studied and-we would addexperimented on. This is rather disconcerting, given the massive number of people that use social media and are in some form or other observed and experimented on by researchers. Perhaps surprisingly, the social media users Kennedy et al. (2015, pp. 3-4) studied seemed to be concerned about privacy, but mainly about social privacy. That is, they wanted to be sure that they could choose which individuals in their network have access to their personal information. They were not so worried about institutional privacy, or "the mining of personal information by social media platforms, commercial companies and governments". Although we are talking about only one study, there is reason to suggest that the ethical criticism of the Facebook experiment made by academics might not reflect users' worries. This is a topic that should be further studied, as it would be relevant for research ethics in the era of social media to be more grounded in the user level. A more holistic and inclusive ethical research study would ensure that researchers do more than define what is morally optimal in big data research; or, as Tama Leaver (2013) states, "Big Data needs Big Ethics, and we don't have them yet."

If we go further into the ethical implications of social media experiments that aim to enhance user experience, we are faced with a more profound ethical challenge than a discussion of manipulation and informed consent reveals. If in Facebook we are fed imagery that further filters our experiences of the "real" world, then what are the ethical ramifications of researchers teaming up with companies that aim to give people "the experience they want" (Simonite, 2012)? Would the companies be in charge of the "hard ethical choice...of what content to show...without oversight, transparency, or informed consent" (boyd, 2014)? The way media and new media influence our perceptions of reality has already been widely studied (e.g. Fairclough, 1995; Macey, Ryan, \& Springer, 2014) but there has been little consideration so far of the ethics of academics taking part in these kinds of studies. 
The way big data is "all at once essential, valuable, difficult to control, and ubiquitous" seems to be reflected in our complex, context-dependent attitudes toward it (Pushcmann \& Burgess, 2014, p. 1695). Gertz (2016, p. 56) notes that despite the Facebook controversy, the number of Facebook users is still growing. At the same time, users' autonomy seems to be diminishing. From this it can be concluded that many users do not mind the asymmetrical relationship they have with the service provider. As Ess (2013, p. 254) notes, "our engagements with new digital media appear to bring in their wake important transformations in our sense of self and identity." Our "foundational conception of autonomous self" that has legitimated concepts of privacy that "modern liberal-democratic" states respect seems to be changing. Perhaps the question we should ask is primarily existential rather than ethical, as Gertz (2016, p. 61) suggests. According to him, we should first think about the increasingly significant role technology plays in our lives. If we accept it, then we can have a more meaningful discussion on the ethics of scholars experimenting with it.

\section{Conflict of Interests}

The authors declare no conflict of interests.

\section{References}

Aiken, M., \& McMahon, C. (2014). A primer of research in mediated environments: Reflections on cybermethodology. SSRN Working Papers. Retrieved from http://papers.ssrn.com/sol3/Papers.cfm?abstract_id $=2462700$

Ananny, M. (2015). Toward an ethics of algorithms: Convening, observation, probability, and timeliness. Science, Technology, and Human Values, 4(1), 93-117.

Bail, C. A. (2015). Taming big data: Using app technology to study organizational behavior on social media. Sociological Methods \& Research. Retrieved from http://smr.sagepub.com/content/early/2015/05/15/ 0049124115587825.full

Barsade, S. (2002). The ripple effect. Emotional contagion and its influence on group behavior. Administrative Science Quarterly, 47(4), 644-675.

Bond, R. M., Fariss, C. J., Jones, J. J., Kramer, A. D. I., Marlow, C., Settle, J. E., \& Fowler, J. H. (2012). A 61million-person experiment in social influence and political mobilization. Nature, 489(7415), 295-298.

boyd, d. (2010, April). Publicity and privacy in web 2.0. Keynote speech at WWW2010, Raleigh, USA. Retrieved from www.danah.org/papers/talks/2010/SX SW2010.html

boyd, d. (2014). What does the Facebook experiment teach us? Growing anxiety about data manipulation. The Message. Retrieved from https://medium.com/ message/what-does-the-facebook-experiment- teach-us-c858c08e287f

boyd, d. (2016). Untangling research and practice: What Facebook's "emotional contagion" study teaches us. Research Ethics, 12(1), 4-13.

The British Psychological Society (2010). Code of human research ethics. Leicester: The British Psychological Society. Retrieved from www.bps.org.uk/sites/de fault/files/documents/code_of_human_research_et hics.pdf

Brotsky, S. R., \& Giles, D. (2007). Inside the "Pro-ana" community: A covert online participant observation. Eating Disorders: The Journal of Treatment \& Prevention, 15(2), 93-109.

Bryman, A., \& Bell, E. (2015). Business research methods. Oxford: Oxford University Press.

Burgess, J., \& Bruns, A. (2015). Easy data, hard data: The politics and pragmatics of Twitter research after the computational turn. In G. Langlois, J. Redden, \& G. Elmer (Eds.), Compromised data: From social media to big data (pp. 93-111). New York: Bloomsbury Academic.

Card, N. A. (2010). Literature review. In N. J. Salkind (Ed.), Encyclopedia of research design (pp. 726-729). Thousand Oaks: Sage.

Ceserani, R. (2010). The essayistic style of Walter Benjamin. Primerjalna književnost, 33(1), 83-92.

Chan, A. (2015). Big data interfaces and the problem of inclusion. Media, Culture \& Society, 37(7), 10781083.

Cheng, J., Adamic, L. A., Dow, P. A., Kleinberg, J., \& Leskovec, J. (2014). Can cascades be predicted? Proceedings of the $23^{\text {rd }}$ International Conference on World Wide Web (pp. 925-936). New York: ACM. Retrieved from http://dl.acm.org/citation.cfm?id=2567 997

Copeland, L. (2011). The anti-social network. Slate. Retrieved from www.slate.com/articles/double_x/dou blex/2011/01/the_antisocial_network.html

Cornelissen, J., Gajewskade, M., Piekkari, R., \& Welch, C. (2012). Writing up as a legitimacy seeking process: Alternative publishing recipes for qualitative research. In S. Gillian \& C. Cassel (Eds.), Qualitative organizational research: Core methods and current challenges (pp. 185-203). London: Sage.

Escobedo, C., Guerrero, J., Lujan, G., Ramirez, A., \& Serrano, D. (2007). Ethical issues with informed consent. Bio-Ethics, 1, 1-8. Retrieved from http://cstep.cs.ut

ep.edu/research/ezine/Ezine-ethicallssueswithlnfor medConsent.pdf

Ess, C. M. (2007). Internet research ethics. In A. Joinson (Ed.), Oxford handbook of internet psychology (pp. 481-502). Oxford: Oxford University Press.

Ess, C. M. (2013). Global media ethics? Issues, requirements, challenges, resolutions. In S. J. A. Ward (Ed.), Global media ethics: Problems and perspectives (pp. 253-271). West Sussex: Wiley-Blackwell. 
Facebook (2015a). Terms of service. Retrieved from www.facebook.com/terms.php

Facebook (2015b). Research at Facebook. Retrieved from https://research.facebook.com

Faden, R. R., \& Beauchamp, T. L. (1986). A History and theory of informed consent. Oxford: Oxford University Press.

Fairclough, N. 1995. Media discourse. London: Bloomsbury.

Ferrara, E., \& Yang, Z. (2015). Measuring emotional contagion in social media. PloS ONE, 10(11). Retrieved from http://journals. plos.org/plosone/article?id=10. 1371/journal.pone.0142390

Fishwick, C. (2014, June 30). Facebook's secret mood experiment: Have you lost trust in the social network? The Guardian. Retrieved from www.theguardian. com/technology/poll/2014/jun/30/facebook-secretmood-experiment-social-network

Flick, C. (2016). Informed consent and the Facebook emotional manipulation study. Research Ethics, 12(1), 14-28.

Friggeri, A., Adamic, L. A., Eckles, D., \& Cheng, J. (2014). Rumor cascades. Proceedings of the Eighth International AAAI Conference on Weblogs and Social Media (ICWSM) (pp. 101-110). Palo Alto, CA: AAAI Press. Retrieved from www.aaai.org/ocs/index.php/ICWSM /ICWSM14/paper/view/8122

Gertz, N. (2016). Autonomy online: Jacques Ellul and the Facebook emotional manipulation study. Research Ethics, 12(1), 55-61.

Grady, C. (2015). Enduring and emerging challenges of informed consent. The New England Journal of Medicine, 372(9), 855-862.

Grimmelmann, J. (2014). As flies to wanton boys. The Laboratorium. Retrieved from http://laboratorium. net/archive/2014/06/28/as_flies_to_wanton_boys

Halavais, A. (2015). Bigger sociological imaginations: Framing big social data theory and methods. Information, Communication \& Society, 18(5), 583-594.

Haney, C., Banks, C., \& Zimbardo, P. (1973). A study of prisoners and guards in a simulated prison. Naval Research Reviews, 30(9), 4-17.

Harman, L. B., \& Cornelius, F. (2015). Ethical health informatics. Burlington, MA: Jones \& Bartlett.

Harriman, S., \& Patel, J. (2014). The ethics and editorial challenges of internet-based research. MBC Medicine, 12, 124-127.

Hesse, B. W., Moser, R. P., \& Riley, W. T. (2015). From big data to knowledge in the social sciences. The Annals of American Academy of Political and Social Science, 659(1), 16-32.

Hine, C. (2000). Virtual ethnography. London: Sage.

Hudson, J. M., \& Bruckman, A. (2004). Go away: Participant objections to being studied and the ethics of chatroom research. The Information Society, 20(2), 127-139.

Huntsinger, J. R., Lun, J., Sinclair, S., \& Clore, G. L. (2009).
Contagion without contact: Anticipatory mood matching in response to affiliative motivation. Personality and Social Psychology Bulletin, 35(7), 909922.

Hutton, L., \& Henderson, T. (2015). “I didn't sign up for this!": Informed consent in social network research. Proceedings of the Ninth International AAAl Conference on Web and Social Media (ICWSM) (pp. 178187). Palo Alto, CA: AAAl Publications. Retrieved from www.aaai.org/ocs/index.php/ICWSM/ICWSM1 5/paper/view/10493

Jouhki, J., Lauk, E., Penttinen, M., Rohila, J., Sormanen, N., \& Uskali, T. (2015, November). Social media personhood as a challenge to research ethics: Exploring the case of the Facebook experiment. Paper presented at the Social Media Research Symposium, Jyväskylä, Finland.

Kahn, J. P., Vayena, E., \& Mastroianni, A. C. (2014). Opinion: Learning as we go: Lessons from the publication of Facebook's social-computing research. Proceedings of the National Academy of Sciences of the United States of America, 111(38), 13677-13679.

Kehr, F., Kowatsch, T., Wentzel, D., \& Fleisch, E. (2015). Blissfully ignorant: The effects of general privacy concerns, general institutional trust, and affect in the privacy calculus. Information Systems Journal, 25, 607-635.

Kennedy, H., Elgesem, D., \& Miguel, C. (2015). On fairness: User perspectives on social media data mining. Convergence: The International Journal of Research into New Media Technologies. Retrieved from http://con.sagepub.com/content/early/2015/06/26/ 1354856515592507.full

Kleinsman, J., \& Buckley, S. (2015). Facebook study. A little bit unethical but worth it? Journal of Bioethical Inquiry, 12(2), 179-182.

Kramer, A. (2014). A post on 29.6.2014. Facebook. Retrieved from www.facebook.com/akramer/posts/10 152987150867796

Kramer, A. D. I., Guillory, J. E., \& Hancock, J. T. (2014). Experimental evidence of massive-scale emotional contagion through social networks. Proceedings of the National Academy of Sciences of the United States of America, 111(24), 8788-8790.

Leaver, T. (2013, September). Birth, death and Facebook. Paper presented at Adventures in Culture in Technology (ACAT) Seminar Series, Perth. Retrieved from www.tamaleaver.net/2013/10/03/birth-death-andfacebook

Lindsay, S., \& Goldring, J. (2010). Anonymizing data for secondary use. In A. J. Mills, G. Durepos, \& E. Wiebe (Eds.), Encyclopedia of case study research (pp. 2527). London: Sage.

Macey, D. A., Ryan, K. M., \& Springer, N. J. (Eds.). (2014). How television shapes our worldview: Media representations of social trends and change. New York: Lexington Books. 
Markham, A., \& Buchanan, E. (2012). Ethical decisionmaking and Internet research. Recommendations from the AolR ethics working committee (version 2.0). Chicago: Association of Internet Researchers. Retrieved from http://aoir.org/reports/ethics2.pdf

Marx, G. T. (2013). An ethics for the new (and old) surveillance. In F. Flammini, R. Stola, \& G. Franceschetti (Eds.), Effective surveillance for homeland security: Balancing technology and social issues (pp. 2-20). Boca Raton, FL: Taylor \& Francis.

McKelvey, F., Tiessen, M., \& Simcoe, L. (2015). A consensual hallucination no more? The Internet as simulation machine. European Journal of Cultural Studies, 18(4-5), 577-594.

Meyer, M. N. (2014). Misjudgments will drive social trials underground. Nature, 511(7509), 265.

Milgram, S. (1963). Behavioral study of obedience. Journal of Abnormal and Social Psychology, 67(4), 371378.

O’Hara, K., Nguyen, M.-H. C., \& Haynes, P. (2014). Introduction. In K. O'Hara, M.-H. C. Nguyen, \& P. Haynes (Eds.), Digital enlightenment yearbook 2014: Social networks and social machines, surveillance and empowerment (pp. 3-24). Amsterdam: IOS Press.

Paolillo, J. C. (2015). Network analysis. In A. Georgakopoulou \& T. Spilioti (Eds.), The Routledge handbook of language and digital communication (pp. 3654). London: Routledge.

Parkinson, B., \& Manstead, A. S. R. (2015). Current emotion research in social psychology: Thinking about emotions and other people. Emotion Review, 7(4), 371-380.

Peacock, S. E. (2014). How web tracking changes user agency in the age of Big Data: The used user. Big Data \& Society, 1(2), 1-11. Retrieved from http:// bds.sagepub.com/content/1/2/2053951714564228

Pejovic, V., \& Musolesi, M. (2015). Anticipatory mobile computing. A survey of the state of the art and research challenges. ACM Computing Surveys, 47(3), 129.

Phillips, M. L. (2011). Using social media in your research. Experts explore the practicalities of observing human behavior through Facebook and Twitter. gradPSYCH, 9(4), 32.

Recuber, T. (2016). From obedience to contagion: Discourses of power in Milgram, Zimbardo, and the Facebook experiment. Research Ethics, 12(1), 44-54.

Roelcke, V. (2004). Introduction: Historical perspectives on human subjects research during the $20^{\text {th }}$ century, and some implications for present day issues in bioethics. In V. Roelcke \& G. Maio (Eds.), Twentieth century ethics of human subjects research: Historical perspectives on values, practices, and regulations (pp. 11-18). Stuttgart: Franz Steiner Verlag.

Rooke, B. (2013). Four pillars of internet research ethics with Web 2.0. Journal of Academic Ethics, 11(4), 265268.
Rosenberg, Å. (2010). Virtual world research ethics and the private/public distinction. International Journal of Internet Research Ethics, 3(1), 23-37.

Rushe, D. (2014, October 2) Facebook sorry-almostfor secret psychological experiment on users. The Guardian. Retrieved from www.theguardian.com/ technology/2014/oct/02/facebook-sorry-secret-psy chological-experiment-users

Schroeder, R. (2014). Big Data and the brave new world of social media research. Big Data \& Society, 1(2), 111.

Searls, D. (2015, November 6). Ad blockers and the next chapter of the Internet. Harvard Business Review. Retrieved from https://hbr.org/2015/11/ad-blocker s-and-the-next-chapter-of-the-internet

Selinger, E., \& Hartzog, W. (2016). Facebook's emotional contagion study and the ethical problem of co-opted identity in mediated environments where users lack control. Research Ethics, 12(1), 35-43.

Shah, D. V., Cappella, J. N., \& Neuman, W. R. (2015). Big data, digital media, and computational social science: Possibilities and perils. The Annals of the American Academy of Political and Social Science, 659(1), 6-13.

Shrader-Frechette, K. (2000). Ethics of scientific research. London: Rowman \& Littlefield.

Simon, J. R. (2014). Corporate research ethics: Whose responsibility? Annals of Internal Medicine, 161(12), 917-918.

Simonite, T. (2012, June 13). What Facebook knows. MIT Technology Review. Retrieved from www.technology review.com/s/428150/what-facebook-knows

Sloan, L., Morgan, J., Burnap, P., \& Williams, M. (2014). Who tweets? Deriving the demographic characteristics of age, occupation and social class from Twitter user meta-data. LloS ONE, 10(3), 1-20.

Sormanen, N., Rohila J., Lauk, E., Uskali T., Jouhki J., \& Penttinen M. (2016). Chances and challenges of computational data gathering and analysis: The case of issue-attention cycles on Facebook. Digital Journalism, 4(1), 55-74.

Stilgoe, J. (2015). Experiment earth: Responsible innovation in Geoengineering. London: Routledge.

Summers-Effler, E., Van Ness, J., \& Hausmann, C. (2015). Peeking in the black box: Studying, theorizing, and representing the micro-foundations of day-to-day interactions. Journal of Contemporary Ethnography, 44 (4), 450-479.

Sun, E., Rosenn, I., Marlow, C., \& Lento, T. (2009). Gesundheit! Modeling contagion through Facebook news feed. Proceedings of the Third International ICWSM Conference (pp. 146-153). Palo Alto, CA: AAAI Publications. Retrieved from http://aaai.org/ocs/in dex.php/ICWSM/09/paper/view/185

Svanteson, D. J. B. (2007). Private international law and the Internet. Alphen aan den Rijn: Kluwer Law International.

Thorson, K., \& Wells, C. (2015). Curated flows: A frame- 
work for mapping media exposure in the digital age. Communication Theory. Retrieved from http://ssc. sagepub.com/content/early/2015/10/19/089443931 5609528.refs

Tinati, R., Halford, S., Carr, L., \& Pope, C. 2014. Big data: Methodological challenges and approaches for sociological analysis. Sociology, 48(4), 663-681.

Torraco, R. J. (2005). Writing integrative literature reviews: Guidelines and examples. Human Resource Development Review, 4(3), 356-367.

Vainio, A. (2012). Beyond research ethics: Anonymity as 'ontology', 'analysis' and 'independence'. Qualitative Research, 13(6), 685-698.

Vanderpool, H. Y. (1996). The ethics of research involving human subjects: Facing the 21st century. Frederick: University Publishing Group.

Verma, I. M. (2014). Editorial expression of concern and correction. Proceedings of the National Academy of
Sciences, 111(29), 10779.

Weeden, M. R. (2012). Ethics and on-line research methodology. Journal of Social Work Values and Ethics, 9(1), 40-51.

Wrzus, C., \& Mehl, M. R. (2015). Lab and/or field? Measuring personality processes and their social consequences. European Journal of Personality, 29(2), 250271.

Zimbardo, P. (1973). On the ethics of intervention in human psychological research: With special reference to the Stanford prison experiment. Cognition, 2(2), 243-256.

Zimmer, M. (2010). "But the data is already public": On the ethics of research in Facebook. Ethics and Information Technology, 12(4), 313-325.

Zwitter, A. (2014). Big Data ethics. Big Data \& Society, 1(2), 1-6.

\section{About the Authors}
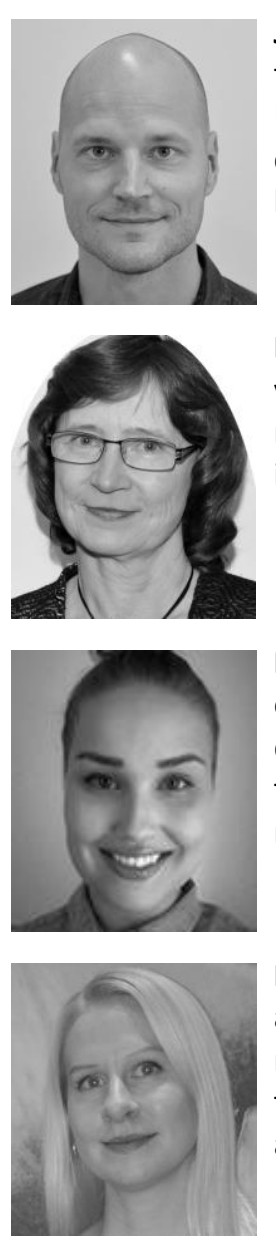

Epp Lauk (PhD) is Professor of Journalism and Head of the Department of Communication at the University of Jyväskylä, Finland. Her research and publications focus on journalism cultures and history, media and journalism in Central and East European countries, media self-regulation and innovations in journalism.

Maija Penttinen is an undergraduate student at the Department of History and Ethnology, University of Jyväskylä. Her research interests include both political participation and civic action on social media, in addition to studying the integration of social networking sites as platforms for everyday activities. She is currently working on her Master's thesis on everyday activities and experiences manifested in research literature concerning the social networking site Facebook.

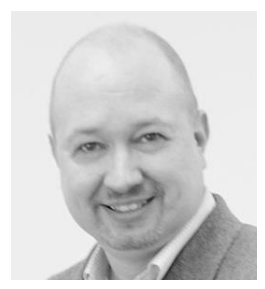

Niina Sormanen (MA) is a PhD candidate of Organizational Communication and Public Relation (PR) at the University of Jyväskylä, Department of Communication. Her research interests include communicative behavior and power relations in the social media context. Her PhD thesis is focused on the interplay of organizational and media professionals and individuals in the social media context and uses of social media in building their communicative power.

Turo Uskali (PhD) is the Head of Journalism and Senior Research Scholar at the Department of Communication, University of Jyväskylä, Finland. He leads several research projects focusing on innovations in journalism. The most recent ones focus on mobile data journalism, and wearables. Uskali is also an Associate Professor at the University of Bergen, Norway, and he has authored or co-authored seven books about the evolution of global journalism and the changes in media industries. 